\title{
Glomerulonefrite a semilune dovuta a trattamento con rifampicina in un paziente con infezione polmonare da micobatterio atipico
}

\author{
Da: Nephron 1998; 78: 319-22 \\ H. Ogata, M. Kubo, K. Tamaki, H. Hirakata, S. Okuda, M. Fujishima
}

$\mathrm{U}$ n uomo di 64 anni si ricovera per calo ponderale e tosse produttiva. All'ascoltazione del torace si rilevano ronchi alla base sn e l'Rx conferma un infiltrato alla base sn. Le ricerche batterioscopiche e colturali sull'escreato risultano positive per Mycobacterium kansasii. Viene instaurata terapia con isoniazide $400 \mathrm{mg} /$ die, rifampicina $150 \mathrm{mg} / \mathrm{die}$ e streptomicina $2 \mathrm{~g}$ im alla settimana. Dopo 5 settimane di terapia si sviluppano edema e versamenti pleurici; la creatininemia sale a $5.9 \mathrm{mg} / \mathrm{dl}$, l'emoglobina scende a $6.9 \mathrm{~g} / \mathrm{dl}$, il sedimento urinario evidenzia cilindri granulari e ialini ed eritrociti, è presente una proteinuria di $3.6 \mathrm{~g} /$ die. Nella norma il complemento, negativi anticorpi anti DNA, anticorpi anti-membrana basale glomerulare e crioglobuline. Modestamente elevati gli immunocomplessi circolanti Clq e C30. La ricerca degli anticorpi contro la rifampicina, condotta con radio-immuno-assay, fornisce esito positivo. Una biopsia renale dimostra glomerulonefrite con semilune e moderati infiltrati interstiziali; negativa l'immunofluorescenza per IgG, IgA, IgM e complemento. In seguito alla sospensione della terapia contro $M$. kansasii la funzione renale lentamente migliora: dopo 4 settimane dalla sospensione della terapia la creatinina risulta $2.7 \mathrm{mg} / \mathrm{dl}$ e viene ripresa terapia con isoniazide ed etambutolo. La funzione renale continua a riprendere: creatinina $1.4 \mathrm{mg} / \mathrm{dl}$ a sei mesi e $1.0 \mathrm{mg} / \mathrm{dl}$ a un anno, con normalizzazione dei reperti urinari.

$\mathrm{Nel}$ caso in questione, la responsabilità della rifampicina nel determinismo della glomerulonefrite rapidamente progressiva è confermata dal ritrovamento di anticorpi circolanti anti-rifampicina, oltre che dalla coincidenza temporale con il trattamento e dalla remissione dell'insufficienza renale sospendendo il farmaco (anche in assenza di terapia cortisonica ed im- munosoppressiva nonostante il reperto istologico di glomerulonefrite a semilune).

Gli effetti collaterali noti della rifampicina comprendono trombocitopenia, emolisi, epatotossicità, gastroenteropatia ed anche insufficienza renale acuta da nefropatia interstiziale e tubulo-interstiziale acuta. La nefrotossicità da rifampicina insorge di solito circa 3 mesi dopo l'inizio della terapia, è considerata una reazione da ipersensibilità e si accompagna alla comparsa di anticorpi circolanti anti-rifampicina; sembra che nel determinismo della patologia giochino un ruolo sia la risposta immunologica primaria che la secondaria.

In precedenza sono stati descritti due soli casi di glomerulonefrite rapidamente progressiva associata a rifampicina ed in nessun caso era stata riscontrata positività degli anticorpi anti-rifampicina, che sono stati dimostrati per la prima volta nel caso descritto dagli Autori, anche se non è chiara la relazione patogenetica tra tali anticorpi e lo sviluppo di semilune. Sembra da escludere una responsabilità della streptomicina (che determina danno tubulare) nella patologia glomerulare in questione. 